\title{
Renal retention of sodium in cirrhosis and fulminant hepatic failure
}

\author{
S. P. Wilkinson \\ B.Sc., M.B., M.R.C.P.
}

A. Alam

M.D.

\author{
Helen MoOdie \\ B.Sc.
}

\author{
Roger WiLliams \\ M.D., F.R.C.P.
}

The Liver Unit, King's College Hospital and Medical School, Denmark Hill, London S.E.5

\begin{abstract}
Summary
Abnormal renal retention of sodium is a characteristic finding in both cirrhosis and fulminant hepatic failure. In cirrhosis the pathogenesis varies according to the level of renal perfusion. When this is normal, hyperaldosteronism is probably the most important factor and this results from an increased release of renin by the kidney. The stimulus to the latter may be a shunting of blood from the outer cortical to juxtamedullary nephrons, although there is no direct relationship between the changes in intrarenal blood flow distribution and sodium excretion. The patients with hyperaldosteronism fail to escape from its sodium retaining effects because of impaired production of natriuretic hormone, which in turn is the result of a failure to expand the 'effective' extracellular fluid volume, because of ascites formation.

In fulminant hepatic failure the site in the nephron of abnormal sodium retention appears to be predominantly the proximal tubule, but its cause is obscure.
\end{abstract}

\section{Cirrhosis}

Abnormal renal retention of sodium is an almost invariable consequence of hepatic cirrhosis. Only two factors have unequivocally been shown to be of importance in its pathogenesis: hyperaldosteronism and, in the late stages of the disease, a reduced renal perfusion. More recently there has been interest in the possible relationship between changes in the intrarenal distribution of blood flow and sodium retention.

The importance of hyperaldosteronism has been the subject of conflicting reports, some reviewers considering this to be the most important initiating factor in sodium retention (Laragh and Ames, 1963) but others giving it only a secondary role (Papper and Vaamonde, 1971). This confusion may have arisen because the significance of hyperaldosteronism has not been considered in relation to different levels of renal perfusion. In this paper, therefore, the results of various studies of sodium excretion in cirrhosis will be separated according to whether total renal perfusion was (i) normal, (ii) markedly reduced, and (iii) moderately reduced.

\section{With normal renal perfusion}

We have recently evaluated the relative roles of changes in intra-renal haemodynamics and hyperaldosteronism in the pathogenesis of sodium retention in a group of patients with cirrhosis in whom the glomerular filtration rate (as measured by inulin clearance) was greater than $90 \mathrm{ml} / \mathrm{min}$ (Wilkinson et al., 1975). All patients had been placed on a strict $50 \mathrm{mEq}$ sodium intake for 4 days before study, and no patient was receiving diuretics or corticosteroids. Sodium excretion ranged from 2 to $74 \mathrm{mEq} /$ day (patients in negative sodium balance were spontaneously losing ascites) and no relation with the GFR could be found in these patients.

As is well known, the human kidney consists of two nephron populations, a group of short outer cortical nephrons and a group of longer juxtamedullary nephrons. It has been suggested that the latter group might have a greater affinity for resorption of sodium and that a redistribution of blood flow from outer cortical to juxtamedullary nephrons could be involved in the pathogenesis of sodium retention (Goodyear and Jaegger, 1955).

Unfortunately, there has been no satisfactory means of determining the intrarenal distribution in man. Thorburn et al. (1963) introduced the technique of inert gas (krypton or xenon) washout and it was hoped that this would be a valid measure of intrarenal blood flow distribution. However, there have been many criticisms of this technique, e.g. Britton, Brown and Bluhm (1971) have pointed out that the basic physical requirements for a multicompartmental analysis of the kidney washout curve are not present, and Slotkoff et al. (1971) were unable to find any correlation between the intrarenal distribution of blood flow, as measured by micro-spheres, with the components of the xenon washout curve. Other 

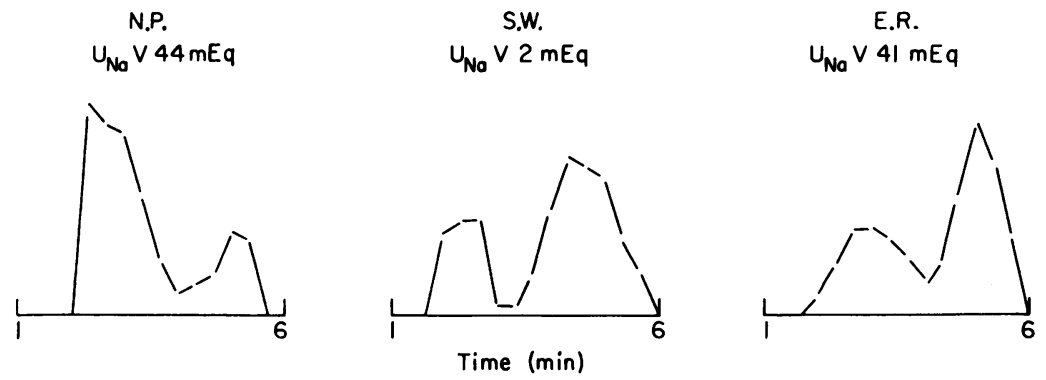

FjG. 1. Distribution of hippuran transits in three patients with cirrhosis. $\left(\mathrm{U}_{\mathrm{Na}} \mathrm{V}-24 \mathrm{hr}\right.$ sodium excretion).

authors have raised theoretical objections to the validity of the technique (Stein et al., 1973).

An alternative technique has been proposed by Britton and Brown (1971). By performing a deconvolution analysis of a ${ }^{131} \mathrm{I}$-hippuran renogram, they have shown that the transit of hippuran through the kidney is bimodal. The early transit (approximately $2.5 \mathrm{~min}$ ) is normally more than three times larger in area than the late transit $(5 \mathrm{~min})$. The early transit has been attributed to the short outer cortical nephrons and the late transit to the long juxtamedullary nephrons. The area representing the transit through the outer nephrons would be expected to be larger than the inner ones, since the outer group constitutes $80 \%$ of the total nephron population. This is the technique we used in the series of patients with cirrhosis already referred to above. In some patients with a normal sodium excretion (e.g. Case 1, Fig. 1), a normal distribution of transits was seen. In Case 2, a patient with severe sodium retention, the area of the first transit was reduced but the second increased, suggesting a redistribution of blood flow from outer cortex to juxtamedulla. However, a similar redistribution was seen in approximately $50 \%$ of the patients with normal sodium excretion (e.g. Case 3, Fig. 1). Thus it was concluded that although an intrarenal redistribution of blood flow occurs in cirrhosis, it is not directly related to sodium excretion. This is the conclusion which has also been reached by a number of workers studying different levels of sodium excretion in various animal preparations, using more direct methods to measure the intrarenal blood flow distribution (e.g. Blantz, Wallin and Rector, 1972; Stein et al., 1971).

Relation to hyperaldosteronism. However, in these studies it was possible to show a hyperbolic relationship between sodium excretion and urinary aldosterone 18-glucuronide (measured by radioimmunoassay), the highest levels of aldosterone being associated with the lowest levels of sodium excretion. Others have found a relationship between sodium retention and elevated urine or plasma levels of aldosterone (Wolff, Koczorek and Buchborn, 1958;
Rossler, Schmeiber and Dölle, 1973). Other evidence also points to an important role for hyperaldosteronism in the pathogenesis of the sodium retention in the patients with cirrhosis who have normal renal perfusion, e.g. adrenalectomy may abolish the so- of dium retention and ascites of cirrhosis (Giuseffi et $N$ al., 1957) and the aldosterone antagonist, spirono- $\mathrm{O}$ lactone, if given in sufficiently high dosage will usually reverse the sodium retention (Eggert, 1970).

If one accepts the importance of hyperaldo-co steronism, there still remain two questions: firstly $\stackrel{5}{\mathcal{D}}$ why do patients with cirrhosis and a normal renad $\overrightarrow{0}$ perfusion have hyperaldosteronism, and secondly ov why do they continue to retain sodium, since the normal response to persistent hyperaldosteronism 15 to 'escape' from its sodium retaining effects.

Although impaired degradation by the liver may be one factor leading to hyperaldosteronism, increased secretion would appear to be quantitatively $\stackrel{\mathbb{Q}}{\Omega}$ more important (Ulick, Laragh and Lieberman, $\overrightarrow{\vec{O}}$ 1958). The latter may be related to a raised intra- 3 hepatic pressure as suggested by Orloff (1970). $\supset$ Hepatic vein occlusion in both man (Budd-Chiari syndrome) and dogs results in hyperaldosteronism, but this is rarely so with portal vein occlusion. The hyperaldosteronism in the dog model can be prevented or reversed by side-to-side portacaval anastomosisa procedure that will decompress a raised intra- $\delta$ hepatic pressure, but not by end-to-side anastomosis, which does not significantly affect intra-hepatic 윽 pressure. In patients with cirrhosis, side-to-side $>$ shunt is more effective in reversing hyperaldosteronism than end-to-side shunt (Orloff, 1970) and $N$ Wolfman, Zuidema and Child (1966) showed that side-to-side shunt is more effective in reversing 0 sodium retention than an end-to-side shunt. How- $-\omega$ ever, this has apparently not been the experience of $\bar{F}$ Reynolds (Schwartz, 1970). In the dog model, Orloffo found that nephrectomy prevented the hyperaldosteronism that follows hepatic vein occlusion, sug- $?$ gesting that the hyperaldosteronism is mediated 0 through the renin-angiotensin system. In other $\frac{P}{\mathbb{D}}$ studies Orloff cross-perfused blood from dogs with $\stackrel{?}{P}$

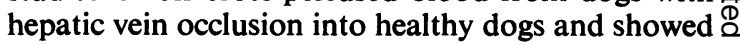


that the recipients also developed hyperaldosteronism, suggesting that there was a humoral mediator to the release of renin.

In our patients we found a close correlation between plasma renin activity and aldosterone excretion, again pointing to the role of the kidney in the mediation of hyperaldosteronism.

In the human kidney, renin occurs almost entirely in the outer cortical nephrons (Cooke and Pickering, 1958). It is possible that a redistribution of blood flow from the outer cortex to the juxtamedullary region might therefore trigger the release of renin, and we found that the patients with a redistribution of blood flow away from the outer cortex, as measured by hippuran transits, had significantly higher values for plasma renin activity than patients with a normal pattern of intrarenal blood flow distribution. The total renal perfusion was similar in the two groups of patients, as measured by inulin and para-aminohippurate clearances.

Failure to escape from the sodium-retaining effects of hyperaldosteronism-role of impaired natriuretic hormone release. Clearly some patients with cirrhosis and hyperaldosteronism do excrete sodium normally, i.e. they show the normal 'escape' phenomenon. We have seen this in two patients and others have also found this (Mann and Siegenthaler, 1964; Rossler et al., 1973). Thus hyperaldosteronism probably occurs before there is evidence of sodium retention. However, most patients with cirrhosis and hyperaldosteronism do continue to retain sodium.

We have recently investigated the mechanisms involved in these differing responses in four patients with cirrhosis without clinically detectable ascites. They were given the mineralocorticoid $9 \alpha$ fluorocortisone, together with a $250 \mathrm{mEq}$ sodium diet for 4 days. On the fourth day, two of the patients were showing the escape phenomenon, with a high urine sodium excretion, but the other two continued to retain sodium and, in these, ascites became detectable. Urine obtained on the 4th day was prepared for 'natriuretic hormone' as described by Sealey, Kirshman and Laragh (1969) and the extract infused into the tail vein of hydrated conscious rats (Brown, Koutsaimanis and de Wardener, 1972). A marked increase in sodium excretion occurred after infusion of the urine extract from the two patients who 'escaped', but not from the two patients who continued to retain sodium.

In these four patients, total extracellular fluid (ECF) was measured using the radiosulphate method, and ascitic volume was determined using ${ }^{125} \mathrm{I}$ albumin in the two patients who failed to 'escape'. In all four patients, total ECF had markedly increased, but when the value for ascitic volume was subtracted it could be seen that 'effective' ECF volume had changed little in those patients who did not 'escape' (Fig. 2). Since effective ECF expansion is thought to be the stimulus in the production of natriuretic hormone, these preliminary data suggest

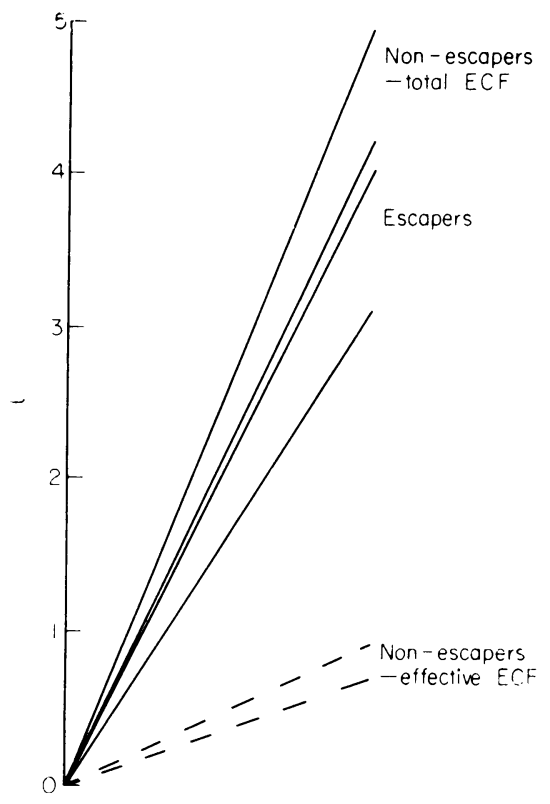

Fig. 2. Extracellular fluid (ECF) volume measurements in four patients with cirrhosis who had been given $9 \alpha$ fluorocortisone plus $250 \mathrm{mEq}$ sodium intake daily for 4 days.

that patients with cirrhosis and hyperaldosteronism may continue to retain sodium because when the effective ECF volume is not expanded, because of ascites formation, this leads to a failure of synthesis or release of natriuretic hormone. Whether or not patients will form ascites when hyperaldosteronism is present, probably depends on other localizing factors such as portal hypertension, decreased plasma albumin concentration and impaired hepatic lymph drainage (Denison, Lieberman and Reynolds, 1971), all of which are known to be important in the formation of ascites.

Mechanism of initiation of ascites formation. At least four factors are known to be involved in ascites formation: increased portal pressure, reduced plasma oncotic pressure, increased hepatic lymph formation and renal retention of sodium. It is generally thought that the first three of these initiate ascites formation and that consequent to the pooling of fluid in the peritoneal cavity, renal perfusion falls and thus the kidneys retain sodium. It is difficult to accept this theory, however, since ascites may be present when total renal perfusion is normal or even high (e.g. four patients with ascites in the series of Baldus, 
Initiation of sodium retention and ascites formation

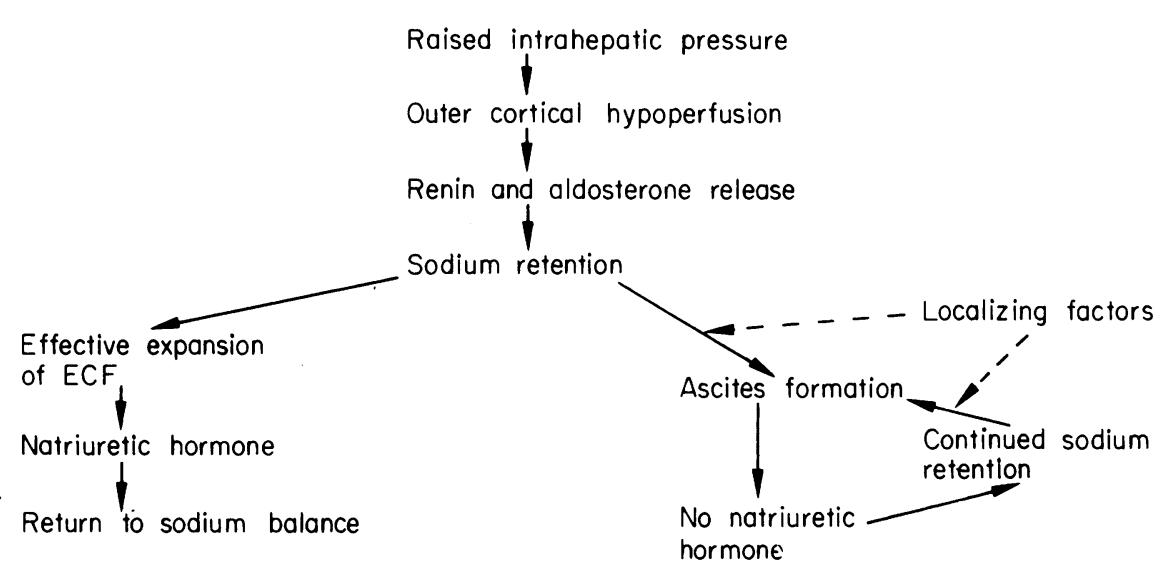

FIG. 3. Proposed mechanism for initiation of ascites formation (ECF-extracellular fluid).

Feichter and Summerskill, 1964, had para-aminohippurate clearances greater than $600 \mathrm{ml} / \mathrm{min}$ ). Liebermann, Denison and Reynolds (1970) have thus proposed that the renal retention of sodium, and therefore water also, may be the primary factor and that this fluid forms ascites because of the localizing factors of portal hypertension, reduced plasma oncotic pressure and increased hepatic lymph formation. They have called this the 'overflow theory'. On the basis of our findings, a scheme is proposed whereby sodium retention and ascites formation are initiated in cirrhosis (Fig. 3). This is a modification of the overflow theory. The first abnormality is the development of a raised intrahepatic pressure, consequent on the cirrhosis, which in turn leads to hypoperfusion of the outer cortical nephrons and thus renin and aldosterone release. Escape from the sodiumretaining effects of hyperaldosteronism will be dependent on whether or not expansion of the effective ECF occurs, which in turn is dependent upon whether ascites forms as a result of the primarily physical factors already mentioned.

\section{Markedly reduced renal perfusion}

In the late stages of cirrhosis, renal perfusion is often markedly reduced (GFR $<25 \mathrm{ml} / \mathrm{min}$ ). The patient is then often said to have 'functional renal failure'. Studies on laboratory animals have shown that such a reduction in renal perfusion induced by a variety of methods is associated with a marked renal retention of sodium and that this is not due to hyperaldosteronism (Thompson and Pitts, 1952). It is therefore unlikely that hyperaldosteronism, even though present in patients with functional renal failure, is of importance in the pathogenesis of sodium retention in such patients. This view is sup- ported by the fact that these patients do not have a natriuresis when given spironolactone.

\section{Moderately reduced renal perfusion}

In practice, many patients will have a moderatel reduced renal perfusion (GFR 20-90 $\mathrm{ml} / \mathrm{min}$. (Baldus et al., 1964). It is thus likely that suct patients will have sodium retention as a result of a combination of hyperaldosteronism and reduced perfusion, the importance of each factor depending on the degree of hyperaldosteronism and level of perfusion in the individual patient.

\section{Fulminant hepatic failure}

There are relatively little data available on renal function in fulminant hepatic failure. We have found a complete range of values for GFR from 1 to 180 $\mathrm{ml} / \mathrm{min}$. All patients with a GFR $<40 \mathrm{ml} / \mathrm{min}$ had sodium retention, as assessed from balance studies, but there was no relationship between sodium excretion and GFR when the GFR was $>40 \mathrm{ml} / \mathrm{min}$ (Wilkinson et al., 1974). All patients in this latter group received relatively large amounts of intravenous sodium (as fresh frozen plasma given as treatment for their coagulation disturbance), and only about $50 \%$ of patients in the latter group were able to excrete this sodium load. The patients with $N$ sodium retention had significantly lower values for both free water clearance and potassium excretion than did the patients excreting sodium normally. These two findings suggest that the site of abnormal $\stackrel{5}{+}$ sodium retention was the proximal tubule and that hyperaldosteronism, even if present, was relatively unimportant. The mechanism for this proximal sodium retention remains to be determined. 


\section{Acknowledgments}

We express our thanks to Drs K. Britton, V. Arroyo, J. D. H. Slater, I. MacFarlane, L. Blendis and to Messrs M. Clark, N. Brown and T. Jowett for help and advice during these studies.

\section{References}

Baldus, W P., Feichter, R.N. \& Summerskill, W.H.J. (1964) The kidney in cirrhosis. II. Disorders of renal function. Annals of Internal Medicine, 60, 366.

BLANTZ, R.C., Wallin, J.D. \& ReCtor, F.C. (1972) Effect of variation in dietary intake on the intrarenal distribution of plasma flow in the rat. Jolirnal of Clinical Investigation, 51, 2790.

Britton, K.E. \& Brown, N.J.G. (1971) Clinical Renography. Lloyd-Luke.

Britton, K.E., Brown, N.J.G. \& Bluhm, M.M. (1971) Xenon washout. Lancet, ii, 822.

Brown, P.R., Koutsaimanis, K.G. \& de Wardener, H.E. (1972) Effect of urinary extracts from salt-loaded man on urinary sodium excretion by the rat. Kidney International, $2,1$.

Cook, W. \& Pickering, G. (1958) Localization of renin within kidney. Journal of Physiology, 143, 78P.

Denison, E.K., Lieberman, F.L. \& Reynolds, T.B. (1971) $9 \alpha$ fluorohydrocortisone induced ascites in alcoholic liver disease. Gastroenterology, 61, 497.

EGGERT, R.C. (1970) Spironolactone diuresis in patients with cirrhosis and ascites. British Medical Journal, 4, 401.

Giuseffi, J., Werk, E.E., Larson, P.U., Schiff, L. \& ElLiotT, D.W. (1957) Effect of bilateral adrenalectomy in a patient with massive ascites and postnecrotic cirrhosis. New England Journal of Medicine, 257, 796.

Goodyear, A.V.N. \& JaEger, C.A. (1955) Renal response to nonshocking haemorrhage: role of the autonomic nervous system and of the renal circulation. American Journal of Physiology, 180, 89.

LaRAGH, J.H. \& Ames, R.P. (1963) Physiology of body water and electrolytes in hepatic disease. Medical Clinics of North America, 47, 587.

Lieberman, F.L., Denison, E.K. \& Reynolds, T.B. (1970) The relationship of plasma volume, portal hypertension, ascites, and renal sodium retention in cirrhosis: the overflow theory of ascites formation. Annals of the New York Academy of Sciences, 170, 202.

ManN, M. \& Siegenthaler, W. (1964) Aldosteronstoffwechsel und Leberkrankheiten. Klinische Wochenschrift, 42, 885 .

Orloff, M.J. (1970) Pathogenesis and surgical treatment of intractable ascites associated with alcoholic cirrhosis. Annals of the New York Academy of Sciences, 170, 213.

PAPPER, S. \& VAAMONDE, C.A. (1971) The kidney in liver disease. In: Diseases of the Kidney (Ed. by M. B. Strauss and L. G. Welt), p. 1139. Little, Brown, Boston.

Rossler, R., Schmeiber, W. \& Dölle, W. (1973). Plasma aldosterone and corticosterone concentration in patients with cirrhosis of the liver. Presented at the Working Party of 'Fluid and Electrolyte Disorders in Liver Disease' at the 8th Meeting of the European Association for the Study of the Liver. Vittel, France, 6-8 September 1973.

Schwartz (1970) In: Discussion. Annals of the New York Academy of Sciences, 170, 236.

Sealey, J.E., Kirshman, J.D. \& Laragh, J.H. (1969) Natriuretic activity in plasma and urine of salt-loaded man and sheep. Journal of Clinical Investigation, 48, 2210.

Slotkoff, L.M., Logan, A., Jose, P., D'Avella, J. \& EISNER, G.M. (1971). Microsphere measurement of intrarenal circulation of the dog. Circulation Research, 28, 158.

Stein, J.H., Boonjarern, S., Wilson, C.B. \& Ferris, T.F. (1973) Alterations in intrarenal blood flow distribution. Circulation Research, 32 (Suppl. 1), 61.

Stein, J.H., Ferris, T.F., Huprich, J.E., Smith, T.C. \& OsGOOD, R.W. (1971). Effect of renal vasodilatation on the distribution of cortical blood flow in the kidney of the dog. Journal of Clinical Investigation, 50, 1429.

Thompson, D.D. \& PitTs, R.F. (1952) Effects of alterations of renal arterial pressure on sodium and water excretion. American Journal of Physiology, 168, 490.

Thorburn, G.D., Kopald, H.H., Herd, J.A., Hollenberg, M., O'Morchoe, C.C.C. \& BARger, A.C.'(1963). Intrarenal distribution of nutrient blood flow determined with krypton $^{85}$ in the unanaesthetized dog. Circulation Research, 13, 290.

Ulick, S., Laragh, J.H. \& Lieberman, S. (1958) The isolation of a urinary metabolite of aldosterone and its use to measure the rate of secretion of aldosterone by the adrenal cortex in man. Transactions of the Association of American Physicians, 71, 225.

Wilkinson, S.P., Arroyo, V., Moodie, H.E., Blendis, L.M. \& Williams, R. (1974) Renal failure and site of abnormal renal retention of sodium in fulminant hepatic failure. Gut, 15, 343 .

Wilkinson, S.P., Smith, I., Arroyo, V., Clark, M., Moodie, H.E. \& Williams, R. (1975) (In preparation).

WolfF, H.P., Koczorek, K.R. \& BuchBorn, E. (1958) Aldosterone and antidiuretic hormone in liver disease. Acta endocrinologica (Copenhagen), 27, 45.

Wolfman, E.F., Zuidema, G.D. \& Child, C.G. (1966) Urinary sodium and aldosterone excretion following portacaval shunts for cirrhosis of the liver and portal hypertension. Annals of Surgery, 164, 538. 